\title{
Research on Customer Viscosity Evaluation Model Based on AHP-ENT-LSM
}

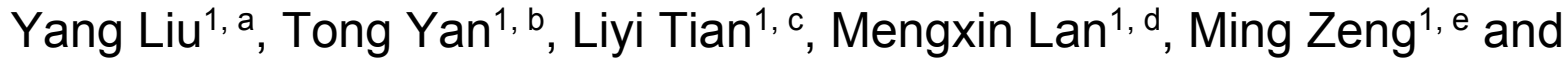 \\ Chundong $\mathrm{Li}^{2, \mathrm{f}}$
}

${ }^{1}$ School of Economics and Management, North China Electric Power University, Beijing 102206, China;

2State Grid Tieling Electric Power Supply Company, Tieling 112000, China.

aliuyang3983@126.com, byantong1208@126.com, ${ }^{c 799079198 @ 126 . c o m, ~}{ }^{d} 75457440 @ q q . c o m$, ezengmingbj@vip.sina.com, jenniferliu@163.com

\begin{abstract}
With the further advance of a new round of electricity market reform, power grid companies are no longer the only power supply main body electric power customer oriented, and replaced by power-retailing companies established by all kinds of investment subject, which makes it necessary to study how to effectively control the customer resources. In view of this, this paper uses the concept of power customer viscosity, and proposes the customer viscosity model of power-retailing company based on AHP-ENT-LSM. First consider customer behavior, customer perception, electric safety, switching cost, customer trust, social image as influencing factors of customer viscosity, and subdivide the six aspects to extract the secondary key indicators. Secondly, based on the advantages of AHP, ENT and LSM, the fuzzy comprehensive evaluation model is constructed. Finally, use some sell power-retailing companies, data to verify the validity of the proposed model. By contrast, the results show that the proposed model can effectively evaluate the electric power customer viscosity, improve the quality of service of the company and provide assistance in making business decisions.
\end{abstract}

Keywords: Power customer viscosity, comprehensive evaluation, power-retailing company, combination weighting.

\section{Introduction}

With the development of the new round of power system reform, the electric power industry faces a more open market environment, which makes the power grid company no longer the sole power supply subject for power customers, sell electricity companies formed by different types of subject that meet the qualification requirements instead. In the fierce market competition, power customers as the source of the profit of the sales company is the focus of various power-retailing companies. It is quit necessary for power-retailing companies to know how to effectively own and control customer resources[1]. For power enterprises with dual nature of public utility and profit, establishing good customer relationship is an important task in the process of business operation. And the establishment of a good customer relationship depends on the customer's satisfaction with the power products and services provided by the power-retailing companies[2-5].

At present, there are many literatures about the optimization decision of engineering project evaluation, mainly focusing on power customer satisfaction. a customer satisfaction evaluation model based on network analytic hierarchy process has been built in [6-8], which only considered the qualitative indicators related to power customer satisfaction, but not considered the relevant quantitative indicators. A comprehensive evaluation method of power customer satisfaction based on the optimization of BP neural network based on fish swarm optimization is proposed in [9-13]. The weights of the indicators are mainly based on the experts' scores, without considering the combination weighting. Electricity customer viscosity measurement model has been established considering switching cost, trust, and security perception, which does not consider the customer's behavioral loyalty of related indicators in [14-16]. Based on the idea of fuzzy comprehensive evaluation [17-20], constructed the user viscosity model under the retail model, but did not consider the subjective and objective combination of weighting in the index weighting. 
Based on previous work, this paper study on the customer viscosity evaluation of the sales company in the open sales environment. First, in consideration of main influence factors such as customer behavior, customer perception, electric safety, switching cost, customer trust and social image, 24 key combination of qualitative and quantitative indicators has been put off. Secondly, a power customer viscosity evaluation model based on AHP-ENT -LSM is established. Finally, the results of the final evaluation on the viscosity of the power customers are compared and analyzed by using the relevant data of the four sales companies. The example verifies the operability and effectiveness of the model constructed in this paper, and provides reference basis for the company to improve service quality and make enterprise decision.

\section{Definition of Power Customer Viscosity}

The word viscosity originates from social network and is an important concept in network marketing, which means the loyalty and dependence of network users, including the number of users' return visits and page stay time. The stronger the user's stickiness, the easier the website will be to play its value[7-9].

In this paper, the concept of viscosity is introduced into the open selling environment, which is used to evaluate the behavior, attitude, emotion and other subjective and objective feelings of power customers[10]. Specifically, affected by a series of factors such as electricity price, power quality and related services, the reliance of power customers on customer viscosity model of power-retailing company means when customers are disturbed by other factors, they can maintain the purchasing behaviors and preferences of the existing sales companies.

\section{Power Customer Viscosity Index System}

In order to make the subjective preference of power customer viscosity scientific, complete and objective, it is particularly critical to construct a comprehensive, feasible and subjective evaluation index system. According to the characteristics of the power industry, the user's viscosity is considered in terms of customer behavior, customer perception, electricity security, conversion cost, customer trust and social image. The six aspects are divided into secondary indicators. Considering the above factors, the evaluation index system of hydropower project is constructed, as shown in table 1.

\section{Combination Weighting Model Based on AHP-ENT-LSM}

Through the combination of qualitative and quantitative analysis, considering the evaluation expert scoring, integrated RS method, AHP method and the weights of the LSM method combinatorial optimization, hydropower project bid evaluation optimization decision model is established.

\subsection{Analytic Hierarchy Process}

Analytic Hierarchy Process is a decision-making related elements into the target, principles, scheme hierarchical weighted decision analysis methods, containing both experts on the importance of subjective judgment and the objective relationship between indexes. The specific steps are as follows.

(1) Constructive judgment matrix. On the basis of considering the logic relation of the lower layer and the lower layer, the judgment matrix is constructed.

(2) Normalization. The eigenvalues $\alpha_{j 2}=\sum_{i=1}^{m}(A \theta)_{i} / n \theta_{i}$ and eigenvectors $\theta_{i}=\phi_{i} / \sum_{i=1}^{m} \phi_{i}, \mathrm{i}=1,2, \mathrm{n}$ of the matrix are calculated by normalization of each element in the matrix.

(3) Consistency check. The random-consistency ratio of the test judgment matrix AT is determined by $\mathrm{AT}<0.1$, and the consistency test was adopted if it was satisfied. Where $A T=A I / T I$ and $A I=\left(\alpha_{j 2}-n\right) /(n-1)$, in stands for the order of the judgment matrix.

(4) Hierarchical order. By using the same level of single order results, the sequence is sorted from top to bottom. 
Table 1. Index system of customer viscosity model of power-retailing company

\begin{tabular}{|c|c|c|c|}
\hline primary index & secondary index & $\begin{array}{l}\text { primary } \\
\text { index }\end{array}$ & secondary index \\
\hline \multirow{2}{*}{ Customer behavior A1 } & Repurchase rate A11 & \multirow{4}{*}{$\begin{array}{c}\text { Customer } \\
\text { dependence A4 }\end{array}$} & $\begin{array}{l}\text { Business portfolio } \\
\text { sophistication A41 }\end{array}$ \\
\hline & Recommendation intention A12 & & $\begin{array}{l}\text { Business proficiency } \\
\text { A42 }\end{array}$ \\
\hline \multirow{6}{*}{ Customer perception A2 } & Resistance to alternative energy A21 & & Price rationality A43 \\
\hline & Quality of service A22 & & $\begin{array}{l}\text { User replacement cost } \\
\text { A44 }\end{array}$ \\
\hline & Promptness of service A23 & \multirow{6}{*}{$\begin{array}{l}\text { Customer trust } \\
\text { A5 }\end{array}$} & Risk tolerance A51 \\
\hline & Comprehensive quality and attitude A24 & & $\begin{array}{l}\text { Expected development } \\
\text { prospects A52 }\end{array}$ \\
\hline & Number of complaints A25 & & $\begin{array}{c}\text { Expected service } \\
\text { capability A53 }\end{array}$ \\
\hline & Service cost performance A26 & & Service execution A54 \\
\hline \multirow{4}{*}{ Electrical safety A3 } & Safety awareness A31 & & $\begin{array}{l}\text { Responsiveness to } \\
\text { requirements A55 }\end{array}$ \\
\hline & Power supply stability A32 & & $\begin{array}{l}\text { Attention that users feel } \\
\text { A56 }\end{array}$ \\
\hline & & & Public popularity A61 \\
\hline & Number of safety accidents A33 & Social image A6 & $\begin{array}{c}\text { Social welfare image } \\
\text { A62 } \\
\text { Service image A63 }\end{array}$ \\
\hline
\end{tabular}

\subsection{Entropy Evaluation Method}

In the field of comprehensive evaluation, entropy value can be used to determine the weight of index information utility value. The specific steps are as follows.

(1) For the obtained s sample, the initial information matrix of t evaluation index $c_{i j} h_{i j} / \sum_{i=1}^{s} h_{i j}$ is determined.

(2) Calculate the entropy of the index.

$$
f_{j}=-g \sum_{i=1}^{s} c_{i j} \operatorname{lnc}_{i j}
$$

Where $g=(\ln m)^{-1}$ and $0 \leq f \leq 1$.

(3) Calculate the difference $p_{j}$ between entropy and 1. For a given index $\mathrm{j}$, the smaller the difference of $h_{i j}$, the larger the $f_{j}$. When complete disorder $f_{j}=1$, the utility value of this information $f_{j}$ is zero for the comprehensive evaluation. And the difference factor vector need to be defined.

$$
V=\left\{V_{1}, V_{2}, \ldots, V_{m}\right\}
$$

Where $V_{i}=1-f_{j}$.

(4) Determine the weight of each indicator. Its essence is to use the value coefficient of this index information to calculate, its value coefficient is higher, the importance to evaluation is bigger. So the weight of the $\mathrm{j}$ index is $v_{j}=p_{j} / \sum^{n} p_{j}$. 


\subsection{LSM Method}

Considering the empowerment of the evaluation index weight deviation as small as possible, use the Least squares Method for integrated optimization of the index weight, and constitute a performance evaluation optimization model.

$$
\operatorname{minL}(\phi)=\sum^{n} \sum^{m}\left\{\left[\left(\theta_{j 1}-\phi_{j}\right) d_{i j}\right]^{2}+\left[\left(\theta_{j 2}-\phi_{j}\right) d_{i j}\right]^{2}\right\}
$$

$$
\text { Set } \sum_{i=1}^{m} \phi_{j}=1, \phi_{j} \geq 0
$$

In the formula, $L(\phi)$ represents the subjective and objective weight deviation; $\phi$ is the combined weight value of the least square method; $\theta_{j 1}$ is the subjective weight value determined by the AHP method; $\theta_{j 2}$ is the objective weight value determined by ENT method; $d_{i j}$ is the equilibrium coefficient, which is usually 0.5 .

\section{Power Customer Viscosity Evaluation Model Based on Fuzzy Comprehensive Evaluation Method}

Fuzzy Comprehensive Evaluation can solve the ambiguity and diversity of Evaluation objects from two perspectives: qualitative and quantitative. In view of the characteristics of qualitative indexes in the evaluation index system of customers' viscosity in the open sales environment, this paper constructs a multi-level FCE customer viscosity evaluation model. The specific steps are as follows.

(1) Determine the evaluation factor set W. Divide all evaluation indexes into $\mathrm{m}$ factor sets and set up factor sets $W=\left\{W_{1}, W_{2}, \ldots W_{m}\right\}$, which makes $W_{i} \bigcap W_{j}=\varnothing,(i \neq j)$. And then $W_{i}$ is divided into sub-factor sets $W_{i}=\left\{W_{i 1}, W_{i 2}, \ldots W_{i n}\right\}$.

(2) Establish the evaluation set $\mathrm{M}$ and construct the membership matrix E. According to the nature and degree of the index, the evaluation set $\mathrm{M}=\{\mathrm{M} 1, \mathrm{M} 2, \ldots, \mathrm{Mn}\}$, each element Mi represents a variety of possible overall evaluation results.

(3) Construct evaluation matrix R, as shown in formula (5).

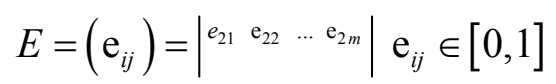

In the formula, eij is the evaluation object of the integrated power customer's opinion, which is the membership of the $\mathrm{j}$ comment $\mathrm{Mj}$ according to the $\mathrm{i}$ factor $\mathrm{Wi}$.

(4) Determine the weight set. The weight vector set $B_{i}=\left\{b_{i 1}, b_{i 2}, \ldots, b_{i n}\right\}$ of each evaluation index in the WI is given.

(5) Make fuzzy comprehensive evaluation. If $\mathrm{m}$ factors of single factor evaluation to the Wi get Ei single factor evaluation matrix, using the same fuzzy operator Ei and weight vector Bi fuzzy synthesis, calculate the Di level factors set Wi evaluation results.

$$
D_{i}=D_{i} \circ E_{i}=\left(d_{i 1}, \mathrm{~d}_{i 2}, \ldots, \mathrm{d}_{i m}\right)
$$

The Wi is treated as a single element, and Di as the single index evaluation vector of the Wi can form the fuzzy evaluation matrix of $\mathrm{W}$ to $\mathrm{M}$.

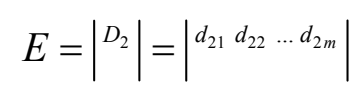

If the weight vector of w1, w2, we is $B_{i}=\left\{b_{i 1}, b_{i 2}, \ldots, b_{i m}\right\}$, and the comprehensive evaluation of $\mathrm{U}$ is:

$$
D=D \circ E=\left(d_{1}, \mathrm{~d}_{2}, \ldots, \mathrm{d}_{m}\right)
$$


(6) Customer viscosity evaluation result of sales company. The fuzzy comprehensive evaluation result $\mathrm{D}$ and the evaluation set $\mathrm{M}$ are fuzzy, and the results of the customer viscosity evaluation of the electric company are sold.

\section{Example Analysis}

In this paper, the customer viscosity of company A, B, C and D is evaluated, and 100 typical customers are involved in the evaluation.

(1) Determine evaluation index set and weight set

The evaluation index set and weight set based on the AHP-ENT-LSM combined weight model are shown in table 2 .

Table 2. The evaluation weight set based on the AHP-ENT-LSM

\begin{tabular}{|c|c|c|c|c|c|c|c|}
\hline primary index & weight & secondary index & weight & primary index & weight & secondary index & weight \\
\hline \multirow{2}{*}{ A1 } & \multirow{2}{*}{0.1} & A11 & 0.5 & \multirow{4}{*}{ A4 } & \multirow{4}{*}{0.1} & A41 & 0.2 \\
\hline & & A12 & 0.5 & & & A42 & 0.15 \\
\hline \multirow{6}{*}{ A2 } & \multirow{6}{*}{0.15} & A 21 & 0.1 & & & A43 & 0.35 \\
\hline & & $\mathrm{A} 22$ & 0.1 & & & A44 & 0.3 \\
\hline & & $\mathrm{A} 23$ & 0.1 & \multirow{6}{*}{ A5 } & \multirow{6}{*}{0.15} & A51 & 0.3 \\
\hline & & A24 & 0.2 & & & A52 & 0.1 \\
\hline & & $\mathrm{A} 25$ & 0.3 & & & A53 & 0.1 \\
\hline & & A26 & 0.2 & & & A54 & 0.15 \\
\hline \multirow{5}{*}{ A3 } & \multirow{5}{*}{0.4} & $\mathrm{~A} 31$ & 0.2 & & & A55 & 0.25 \\
\hline & & A 32 & 0.4 & & & A56 & 0.1 \\
\hline & & & & & & A61 & 0.3 \\
\hline & & A33 & 0.4 & A6 & 0.1 & A62 & 0.3 \\
\hline & & & & & & A63 & 0.4 \\
\hline
\end{tabular}

(2) Establishment of evaluation set

According to the nature and degree of the evaluation index, it is divided into five grades, and the evaluation set is $\mathrm{M}=\{\mathrm{M} 1, \mathrm{M} 2, \ldots, \mathrm{M} 5\}, \mathrm{Mj}$ is the score of the $\mathrm{j}$ grade. $\mathrm{Mj}=\{$ excellent $[80,100]$, good $[60,80]$, medium $[40,60]$, poor $[20,40]$, bad $[0,20]\}$. The upper limit value of the grade score interval is composed of the evaluation set: $\mathrm{M}=\{\mathrm{M} 1, \mathrm{M} 2, \ldots, \mathrm{M} 5\}=\{100,80,60,40,20\}$.

(3) Construct the membership matrix

For example, the evaluation results of 100 power customers are obtained by means of the sales company A, and the following fuzzy membership matrix is obtained by means of average, as shown in table 3.

(4) Fuzzy comprehensive evaluation

According to the weight value of each index, the fuzzy comprehensive evaluation matrix $\mathrm{R}$ of the first level factor set is obtained by using the weighted average operator.

$$
\begin{gathered}
D_{1}=B \circ E=(0.25,0.375,0.3125,0.0625,0) \\
D_{2}=B \circ E=(0.2625,0.22,0.3,0.2175,0) \\
D_{3}=B \circ E=(0.3,0.45,0.25,0,0) \\
D_{4}=B \circ E=(0.325,0.375,0.375,0.025,0) \\
D_{5}=B \circ E=(0.29375,0.41875,0.275,0.0125,0) \\
D_{6}=B \circ E=(0.25,0.25,0.4125,0.0875,0)
\end{gathered}
$$

The above evaluation vector is used as the upper index evaluation matrix, and the secondary fuzzy comprehensive evaluation value is obtained. Then, the second-level fuzzy comprehensive index value of the company is as follows:

$$
D_{A}=(0.2809,0.3683,0.18,0.1708,0)
$$


Table 3. Fuzzy membership matrix

\begin{tabular}{ccccccc}
\hline primary index & secondary index & excellent & good & medium & poor & bad \\
\hline \multirow{2}{*}{ A1 } & A11 & 0.25 & 0.5 & 0.25 & 0 & 0 \\
& A12 & 0.25 & 0.25 & 0.375 & 0.125 & 0 \\
& A21 & 0.25 & 0.375 & 0.375 & 0 & 0 \\
A2 & A22 & 0.25 & 0.5 & 0.25 & 0 & 0 \\
& A23 & 0.375 & 0.375 & 0.25 & 0 & 0 \\
& A24 & 0.25 & 0.5 & 0.25 & 0 & 0 \\
& A25 & 0.25 & 0.25 & 0.375 & 0.125 & 0 \\
A3 & A26 & 0.25 & 0.375 & 0.375 & 0 & 0 \\
& A31 & 0.25 & 0.5 & 0.25 & 0 & 0 \\
& A32 & 0.375 & 0.375 & 0.25 & 0 & 0 \\
A4 & A33 & 0.25 & 0.5 & 0.25 & 0 & 0 \\
& A41 & 0.25 & 0.25 & 0.375 & 0.125 & 0 \\
& A42 & 0.5 & 0.25 & 0.25 & 0 & 0 \\
& A43 & 0.25 & 0.5 & 0.25 & 0 & 0 \\
& A44 & 0.375 & 0.375 & 0.25 & 0 & 0 \\
& A51 & 0.25 & 0.5 & 0.25 & 0 & 0 \\
& A52 & 0.25 & 0.25 & 0.375 & 0.125 & 0 \\
& A53 & 0.25 & 0.375 & 0.375 & 0 & 0 \\
& A54 & 0.25 & 0.5 & 0.25 & 0 & 0 \\
& A55 & 0.375 & 0.375 & 0.25 & 0 & 0 \\
& A56 & 0.375 & 0.375 & 0.25 & 0 & 0 \\
& A61 & 0.25 & 0.25 & 0.375 & 0.125 & 0 \\
& A62 & 0.25 & 0.25 & 0.5 & 0 & 0 \\
& A63 & 0.25 & 0.25 & 0.375 & 0.125 & 0 \\
\hline & & & & & & 0
\end{tabular}

Similarly, the final evaluation results of other sales companies are as follows. Company B:

$$
D_{B}=(0.1543,0.3512,0.2516,0.1257,0.1123)
$$

Company C:

$$
D_{C}=(0.3151,0.2453,0.2052,0.2451,0.064)
$$

Company D:

$$
D_{D}=(0.215,0.1816,0.225,0.335,0.097)
$$

(5) Comprehensive evaluation result

According to the principle of maximum membership, the comprehensive membership value of the company is 0.3683 , and the evaluation is "good". Therefore, about $36.83 \%$ of the power customers are satisfied with the overall strength of the company. Similarly, sold electric company's integrated membership degree value of 0.3512 , comments as "good", c to sell the company's comprehensive membership degree value of 0.3151 , comments as "optimal", butyl sell electricity company's comprehensive membership degree value of 0.335, comments as "poor".

(6) Evaluation result analysis

In order to compare the customer viscosity evaluation results of various sales companies, the membership degree is converted to the score by the central value method, and finally the power customer viscosity evaluation score of the sales company a was 63.206. And the final scores of the sales company B, C and D are 55.945, 63.783 and 54.464 respectively.

Compared the evaluation results of four sales companies, it can be seen that the company $\mathrm{C}$ is superior in terms of membership evaluation, and the overall score is the highest, so the customers of the company $\mathrm{C}$ is the highest. 


\section{Conclusion}

In this paper, the customer viscosity evaluation model based on AHP-ENT-LSM is put forward in the context of open sales environment. In view of the problems of qualitative and quantitative indexes in the customer viscosity index, the combination and empowerment of AHP, ENT and LSM are used to increase the real validity of the evaluation results. Considering customer behavior, customer perception and behavior, safe electricity utilization factor, this paper determines 6 primary indexes, 24 secondary indexes, and sell electricity company customer viscosity evaluation index system is constructed. Thus customer viscosity evaluation model based on multilevel fuzzy comprehensive evaluation method is established. The results show that the customer viscosity evaluation model based on AHP-ENT-LSM is able to comprehensively evaluate the customer viscosity of the future sales company from various angles. At the same time, the application of comprehensive empowerment and fuzzy comprehensive evaluation method quantified the qualitative indexes as far as possible. The results of the example verify the effectiveness of the proposed method, and provide the decisionmaking support for the targeted improvement of the power supply service.

\section{Acknowledgments}

This work was financially supported by Research and Application of Supporting the competitiveness of electricity sales service of Energy-saving and Low-carbon Value-added service technology under the open electricity sales environment.

\section{References}

[1]. Zeng Ming, Wu Gang, Wang Hoaxing, et al. Regulation Strategies of Demand Response Considering User Satisfaction Under Smart Power Background [J]. Power System Technology, 2016, 40 (10): 2917-2923.

[2]. Zhou Laisha, Yu Xinhua. Fuzzy Comprehensive Evaluation of Power Customer Satisfaction Based on Analytic Network Process [J]. Power System Technology, 2009, 33(17):191-197.

[3]. Yang Shania, Han Qi, Xu Indian, et al. Comprehensive Evaluation of Electric Power Customer Satisfaction Based on BP Neural Network Optimized by Fish Swarm Algorithm[J]. Power System Technology, 2011, 35(5):146-151.

[4]. Du Penghu, Chen Kinging, Tan Songful. The Research on Customer Viscosity Based on the Retail Competition Mode [J]. Journal of North China Electric Power University (Social Sciences), 2015, No.93(1):48-52.

[5]. Ding Ming. Evaluation of the Electricity Customer Stickiness in Retail Mode[D]. North China Electric Power University, 2015.

[6]. Wang Jian fang, Zhao Men, Gao Mei, et al. Based on RSM and SMAA's Chinese Smart City People Evaluation - Taking Beijing and Tianjin as Examples[J]. Technology Economic, 2018, 37(3).

[7]. Ren Bauru. Credit Evaluation of Electricity Customers Based on Fuzzy Synthetic Evaluation Method[J]. Modern Electric Power, 2011, 28(4): 90-94.

[8]. Zhou Kai, Li Queue, Zhou Lin, et al. Credit Evaluation of Large Power Consumers Based on Matter-Element Analysis Theory [J]. Power System Technology, 2009, 33(16):75-80.

[9]. Liu Tingyi. Comprehensive evaluation research of safety and healthy environ. Mint for Power construction based on fuzzy math [J]. Electronic Test, 2014(2):20-21.

[10]. Pang Don Sheng. How to increase the viscosity of Internet customers[J]. New Marketing, 2014, 41(5):21-21. 
[11]. Zhang Kaifeng, Zhang Zhou. Construction and determination of characteristic indexes in the technical life cycle stage [J]. Technology Economics, 2018, 37(2):108-112.

[12]. Chi Ge. The impact of China's foreign direct investment on the global value chain is based on the empirical analysis of gravy correlation theory [J]. Journal of Industrial Technological Economics, 2018(5):88-96.

[13]. Kong Bo. The application of the improved multi-objective fuzzy evaluation method in the comprehensive evaluation of water-saving reconstruction in irrigated areas [J]. Technical Supervision in Water Resources, 2018, 49(1):160-162.

[14]. Ma Changing, He Ming. The Application of Fuzzy Comprehensive Evaluation Based on Analytic Hierarchy Process in Military Master Cultivation Quality Evaluation [J]. Value Engineering, 2018, 85(7):201-204.

[15]. Qian Chua, Wu Jialing. The supplier selection model based on Bayesian network and TOPSIS [J]. Journal of Industrial Technological Economics, 2018(4).

[16]. Wang HI, Liu Shenzhen, Xu Son. Evaluation Model for Demand-Side Response Resource Value Based on Entropy and TOPSIS [J]. East China Electric Power, 2014, 42 (1):143-149.

[17]. Chen Jin, Zhao Chuang, and JIA Xiao, et al. Reconstructing the evaluation system of enterprise technology innovation ability: from knowledge management to value creation [J]. Technology Economics, 2017, 2017 (9):1-8.

[18]. Sheila Nolan, Mark O'Malley. Challenges and barriers to demand response deployment and evaluation [J]. Applied Energy, 2015, 152:1-10.

[19]. A Mara, C Tar, R Spellman, CJ Vörösmarty, JE Mack nick... Mack nick. The power of efficiency: Optimizing environmental and social benefits through demand-side-management [J]. Energy, 2014, 76:502-512.

[20]. Khatri D. Mistry, Ramjet Roy. Impact of demand response program in wind integrated distribution network [J]. Electric Power Systems Research, 2014. 